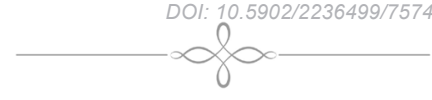

\title{
A relação da Geografia e o conhecimento cotidiano vivido no lugar
}

Laudenides Pontes dos

Santos*

Resumo: Este artigo consiste em uma análise de como o cotidiano dos alunos, pode ser utilizado nas aulas de geografia. Esta pesquisa tem como foco a relação entre a realidade mais próxima do aluno e o conhecimento geográfico, no ensino médio. Como objetivo principal, buscou-se entender como o lugar do aluno ou suas vivências podem ser mobilizadas na educação geográfica, usando como ponto de partida a discussão do lugar. O Lugar é a categoria geográfica que se refere ao espaço vivido, onde se estabelecem as relações de pertencimento. A pesquisa realizou-se em 03 escolas da rede estadual de ensino da cidade de Teresina-PI, com aplicação de questionários para 279 alunos. Constatou-se a riqueza das vivências dos alunos a partir do lugar onde vivem $e$ como eles têm a contribuir nas aulas de Geografia.

\section{The relationship between geography and knowledge daily lived in the place}

\footnotetext{
Abstract: This article is an analysis of how the daily lives of students are used as in geography lessons. This survey focusing on the relationship between the reality closer to the student and the geographical knowledge, in high school. The main objectives sought to understand how the students' place or their experiences can be mobilized in geographical education, using as a starting point to discuss this place. The Place is a geographical category that refers to the living space where the closer relationships are established. The methodology applied was field research in 03 state schools of the city of Teresina-PI, with the application of questionnaires to 279 students.. It was found how rich are the experiences of the students from the place they live and how much they have to contribute in geography lessons.
}

Professora de Geografia do Instituto Federal do Piauí. Doutoranda em Geografia pela Universidade Estadual Paulista UNESP 


\section{Introdução}

Constitui objeto do presente artigo discutir de que forma se relaciona o "lugar" e a construção de conhecimentos geográficos através de uma análise da relação entre as vivências sócio-espaciais do aluno e a Geografia ensinada. Em outras palavras, buscou-se entender como 0 aluno consegue relacionar a Geografia apreendida na escola com o seu cotidiano.

Partimos do pressuposto de que os agentes do processo de ensino-aprendizagem, alunos e professores, pertencem a um meio social, pelo qual são influenciados e, no qual, certamente, exercem influências. A relação com esse meio perpassa aspectos sociais, econômicos, culturais, históricos, religiosos, o que acaba por tornar cada lugar único, particular, dono de uma identidade própria.

A relação do sujeito com o seu lugar é dinâmica, e embora se dê em escala local, interage com contextos mais amplos, do que aquele efetivamente, vivido por cada um. O lugar seria então a parte do mundo vivida pelo sujeito, nas palavras de Santos: "Os lugares são, pois, o mundo, que eles reproduzem de modos específicos, individuais, diversos. Eles são singulares, mas são também globais, manifestações da totalidade-mundo, da qual são formas particulares." (2000a, p.112).

Ao resgatar o lugar que o aluno mora, suas vivências, suas relações com o espaço e com a sociedade, a Geografia torna-se mais próxima, pois pode ultrapassar a teoria trazida nos livros, uma vez que pode ser associada ao convívio social e alargar as possibilidades de ensino. Aproveitar a fala e as experiências dos alunos é considerá-lo sujeito ativo no processo de ensino-aprendizagem, não mais como um receptor de informações prontas, mas como um sujeito que pode contribuir para a construção do conhecimento.

É no lugar que o aluno vive intensamente os processos sociais, onde se relaciona mais intensamente com as pessoas e até mesmo com o próprio espaço geográfico. Nele, são construídas relações identitárias e até mesmo de pertencimento. É por esse motivo que consideramos indispensável que o "lugar" ou os espaços próximos do aluno também sejam levados em consideração no ensino da Geografia. Através dele se entra em contato com o mundo, como aprendemos na teoria de Santos: "O lugar é um ponto do mundo onde se realizam algumas das possibilidades deste último. O lugar é parte do mundo e desempenha um papel em sua história." (SANTOS, 1988, p.35).

Nesse sentido, à disciplina Geografia cabe não somente levar o aluno a um entendimento da dimensão espacial da sociedade como um todo, mas, encontrar meios de contextualizar esse ensino, considerando também o espaço vivido do/pelo aluno, uma vez que é relevante que ele entenda sua própria realidade e os fatores que influenciam diariamente sua vida. Consideramos, portanto, que o aluno traz consigo, para dentro da escola, experiências de vida conforme o seu lugar, a sua realidade social; sendo o lugar um espaço vivenciado, possui uma cultura geográfica.

Neste sentido, é relevante, ainda que não suficiente, para os professores de Geografia enfrentar o desafio de se considerar, entre outras, a "cultura geográfica" dos alunos. Na prática cotidiana, os alunos constroem conhecimentos geográficos. É preciso considerar esses conhecimentos e a experiência cotidiana dos alunos, suas representações, para serem confrontados, discutidos e ampliados com 0 saber geográfico mais sistematizado (que é a cultura escolar) (CAVALCANTI, 2005, p. 68).

Geografia Ensino \& Pesquisa, v. 16, n.3 p. 107-122 set./dez. 2012.

A relação da Geografia e o conhecimento cotidiano vivido no lugar
As interpretações geográficas podem possibilitar a discussão de várias nuances da vida em sociedade, entre elas, os problemas sociais que atingem grande parte da população brasileira: o desemprego, a violência, problemas urbanos, os descasos com o meio ambiente, a exclusão trazida com as novas tecnologias e a necessidade cada vez maior de uma educação de qualidade para se preparar para um mundo global, onde a tecnologia avança e torna os menos preparados, excluídos. Esses temas devem ser tratados em sala de aula, pois fazem parte da vida dos alunos e 
"é imprescindível que o seu ensino, já no $1^{\circ}$ e $2^{\circ}$ graus, atente para a observação e a necessidade de explicação de questões que a realidade coloca, cotidianamente" (VLACH, 1991, p. 41)

A ideia de relacionar as experiências dos alunos em seu cotidiano com os conteúdos de Geografia se torna possível pelos aspectos inerentes a essa ciência que discute as relações do indivíduo com o seu meio, como vemos em Callai:

O conteúdo de Geografia, por ser essencialmente social e ter a ver com as coisas concretas da vida, que estão acontecendo e tem sua efetivação num espaço concreto aparente e visível, permite e encaminha o aluno a um aprendizado que faz parte da própria vida e como tal pode ser considerado em seu significado restrito e extrapolado para condição social da humanidade. (2001, p. 143)

Acreditamos que essa perspectiva de se discutir o espaço vivido dos alunos é uma forma de ligar os acontecimentos do mundo, que por muitas vezes são contraditórios, com as experiências dos alunos no seu lugar. As vivências podem contribuir muito para a compreensão dos conteúdos científicos, em contrapartida um melhor aprendizado pode resultar em ações mais conscientes e críticas do aluno no seu dia a dia: "É do confronto dessa dimensão do vivido com o concebido socialmente - os conceitos científicos - que se tem a possibilidade da reelaborarão e maior compreensão do vivido, pela internalização consciente do concebido." (CAVALCANTI, 2001, p. 148).

A discussão sobre a importância de se resgatar a experiência de vida dos alunos no processo de ensino-aprendizagem, já foi debatida por vários autores como: Resende (2002), Callai (2001, 2005), Cavalcanti (2002), Freire (2001), Castellar (2000), Kaercher (2003), Oliveira (2001), Sacramento (2007). No momento em que se valoriza a realidade do grupo de alunos, resgata-se a sua história e sua identidade. Discutindo um espaço que bem conhecem, dessa forma, podem construir conceitos mais amplos, facilitando o seu aprendizado, o que pode levá-los a uma maior compreensão do seu papel como sujeitos ativos na construção do espaço em que vivem.

Considerando que cada aluno possui uma gama de conhecimentos adquiridos na sua vivência sócio-espacial e que quando esta é considerada pode-se chegar a um melhor entendimento dos conhecimentos em Geografia, queremos entender como essas vivências são mobilizadas pelos alunos na educação geográfica; dessa forma, usaremos como ponto de partida a discussão do lugar do aluno (que é onde acontece a maioria das suas relações sociais).

Nessa perspectiva, pretendemos contribuir para entender como essa prática está presente no Ensino Médio e de que forma ela pode tornar o processo de ensino-aprendizagem em Geografia mais eficaz. Acreditamos que a relevância deste estudo consiste, principalmente, em ampliar as discussões relativas a essa possibilidade para a prática docente do professor de Geografia.

\section{Metodologia}

Para a realização desta pesquisa optamos por uma abordagem metodológica quantiqualitativa, uma vez que nos pautamos em dados quantitativos e qualitativos para fazermos nossas análises. 0 instrumento utilizado nesta pesquisa foi o Questionário de Perguntas Abertas e Fechadas (RICHARDSON et al., 2007).

Os procedimentos adotados na pesquisa foram os seguintes: Visitação às três escolas estudadas para apresentação da proposta de pesquisa, aplicação dos questionários com 279 alunos, tabulação dos dados quantitativos e organização das tabelas e análise dos dados qualitativos e disposição dos resultados em tabelas.

A análise dos dados foi feita em duas etapas: a primeira se constituiu na observação das freqüências dos dados quantitativos das respostas, que foram tabulados e dispostos em tabelas e a segunda foi a análise destes dados.

Geografia Ensino \& Pesquisa, v. 16, n.3 p. 107-122 set./dez. 2012.

Santos, L. P. 
Os dados qualitativos colhidos nas perguntas abertas dos questionários foram analisados através da Análise de Conteúdo, que visou à identificação dos elementos que se repetiam nas respostas para então estabelecer categorias de análise acerca da construção de conhecimento geográfico e sua relação com as vivências sócio-espaciais do aluno, buscando-se assim responder nossa questão- identificar como o lugar e as vivências do aluno podem se tornar elementos norteadores de discussões nas aulas de Geografia no ensino médio.

A análise se organizou nas seguintes fases: uma leitura do material coletado; a definição de categorias conforme as respostas dadas pelos alunos; 0 tratamento quantitativo dessas respostas de modo a sabermos como apareciam através de cálculos de freqüências e porcentagens e sua disposição em tabelas conforme as categorias pré-estabelecidas; a interpretação qualitativa desses resultados.

0 campo da nossa investigação se constituiu de três escolas da rede estadual de ensino da cidade de Teresina-PI: Colégio Estadual Zacarias de Góis (Liceu Piauiense), Unidade Escolar Professora Maria de Lourdes Rebelo e a Unidade Escolar Santa Inês. A escolha dessas escolas se deu pelo critério da sua localização geográfica na cidade de Teresina, por atenderem alunos de diferentes regiões. Foram aplicados questionários com 279 alunos, dos turnos diurnos e noturnos nas três escolas.

O Colégio Estadual Zacarias de Góis está localizada no centro da cidade de Teresina-PI, é mais conhecido como Liceu Piauiense. Trata-se de uma escola tradicional, pois foi e continua sendo uma peça importante da história da educação piauiense, contando com mais de cem anos de serviços prestados. A escola atende praticamente alunos oriundos de toda a cidade, portanto, podemos afirmar que podemos encontrar grande diversidade no alunado dessa escola.

Foram aplicados 113 questionários, no Liceu Piauiense, em três turmas ( $\left(1^{\mathrm{a}}, 2^{\mathrm{a}}\right.$ e $3^{\mathrm{a}}$ séries), nos turnos manhã e tarde, o que corresponde a $5,2 \%$ dos alunos matriculados na escola no ano letivo de 2009.

A escola Maria de Lourdes Rebelo fica localizada, no bairro de Fátima, zona leste da cidade de Teresina, foi fundada em 1972, perfazendo trinta e sete anos de existência. A escola oferece 0 ensino médio nos turnos manhã, tarde e noite. Atualmente a escola atende a 915 alunos distribuídos nos três turnos. Esse público é proveniente, sobretudo, de bairros vizinhos ao bairro de Fátima, como Satélite, Vila Maria, Piçarreira, Planalto Uruguai.

Na Unidade Escolar Professora Maria de Lourdes Rebelo, a pesquisa se deu com 77 alunos das três séries do ensino médio, nos turnos manhã, tarde e noite. Nesta escola observou-se um grande número de alunos trabalhadores.

A Unidade Escolar Santa Inês localizada no bairro Dirceu Arcoverde I, zona sudeste de Teresina, foi fundada no dia 13 de agosto de 1993. A escola oferece o ensino fundamental da primeira à sexta serie, no turno diurno e o ensino médio no período da noite. Atualmente a escola possui 841 alunos, cursando o ensino médio são 277. Esses alunos são provenientes de vários bairros da região sudeste, como: Dirceu Arcoverde I e II, Renascença I II e III, Alto da Ressurreição, Parque Ideal, Parque Itararé, Novo Horizonte, dentre outros.

Foram aplicados na Unidade Escolar Santa Inês 89 com alunos das três séries do ensino médio, somente do turno da noite. Observou-se também nesta escola muitos alunos trabalhadores.

\section{Resultados}

Geografia Ensino \& Pesquisa, v. 16, n.3 p. 107-122 set./dez. 2012.

A relação da Geografia e o conhecimento cotidiano vivido no lugar
Passamos agora a analisar de que forma os alunos pesquisados se relacionam com a escola, com o estudo, com a disciplina Geografia, com o lugar onde moram e ainda de que forma fazem a relação entre essa disciplina e o seu cotidiano e como percebem a Geografia na sua própria realidade, no lugar onde vivem.

Nesse momento, utilizaremos dados quantitativos, analisando os dados que estarão dispostos em tabelas e também discutiremos as respostas desses alunos a questões subjetivas, que foram analisadas e agrupadas em categorias, usando como base a análise de conteúdo. 
O primeiro questionamento foi como os alunos pesquisados concebem a importância da escola com o objetivo de entender a relação destes com o ambiente escolar; quando feita essa pergunta, os alunos responderam livremente e suas assertivas foram agrupadas em categorias que estão apresentadas na Tabela 1, a seguir:

Tabela 01 - Distribuição dos alunos, pos escola, segundo justificativas em relação à importância da escola

\begin{tabular}{|c|c|c|c|c|}
\hline \multirow[t]{2}{*}{ PONTOS CITADOS PELOS ALUNOS } & \multicolumn{4}{|c|}{ RESPOSTAS DOS ALUNOS POR ESCOLA } \\
\hline & ESCOLA 1 & ESCOLA 2 & ESCOLA 3 & TOTAL \\
\hline \multirow{2}{*}{$\begin{array}{l}\text { Relacionados com a formação da cidadania, } \\
\text { do caráter e de bons valores }\end{array}$} & $14,2 \%$ & 0 & $8,0 \%$ & $8,2 \%$ \\
\hline & 16 & 0 & 7 & 23 \\
\hline \multirow{2}{*}{$\begin{array}{l}\text { Relacionados com a preparação para } 0 \\
\text { vestibular e para o mercado de trabalho }\end{array}$} & $8,8 \%$ & $9,0 \%$ & $11,0 \%$ & $9,7 \%$ \\
\hline & 10 & 7 & 10 & 27 \\
\hline \multirow{2}{*}{$\begin{array}{l}\text { Relacionados com a perspectiva de um futuro } \\
\text { melhor }\end{array}$} & $31,9 \%$ & $30 \%$ & $27 \%$ & $29,7 \%$ \\
\hline & 36 & 23 & 24 & 83 \\
\hline \multirow{2}{*}{$\begin{array}{l}\text { Relacionados com } 0 \text { aprendizado e } \\
\text { desenvolvimento intelectual }\end{array}$} & $33,6 \%$ & $55,8 \%$ & $40,4 \%$ & $42 \%$ \\
\hline & 38 & 43 & 36 & 117 \\
\hline \multirow{2}{*}{$\begin{array}{l}\text { Relacionado com a interação e convívio } \\
\text { social }\end{array}$} & $7,0 \%$ & $1,2 \%$ & $8,0 \%$ & $5,7 \%$ \\
\hline & 8 & 1 & 7 & 16 \\
\hline \multirow{2}{*}{$\begin{array}{l}\text { Relacionado com a aprendizagem para o dia } \\
\text { a dia }\end{array}$} & $4,5 \%$ & $4 \%$ & $5,6 \%$ & $4,7 \%$ \\
\hline & 5 & 3 & 5 & 13 \\
\hline Total & 113 & 77 & 89 & 279 \\
\hline
\end{tabular}

Fonte: Pesquisa direta, maio 2009.

Constatamos as mais variadas justificativas sobre a importância da escola, que foram englobadas nas categorias acima descritas. 0 motivo que predominou foi a escola ser importante, por proporcionar aprendizado e desenvolvimento intelectual, que foi citado por 117 alunos. 0 segundo maior número de respostas (83) foi a escola ser importante para se ter um futuro melhor.

Outras justificativas menos apontadas foram: a escola ser importante na preparação para a cidadania (23 respostas), qualificação para o vestibular e mercado profissional (27), ajudar na interação e convívio social (16) e ainda adquirir conhecimentos para o dia a dia (13).

Destacamos a escola vista não somente como um lugar onde se adquire apenas conhecimentos para a preparação para o mercado de trabalho, mas também o seu papel na formação de cidadãos, ou seja, quando atua preocupada com o surgimento de bons valores e comportamentos preocupados com o bem-estar social, além disso, voltada também para a vida prática, ajudando ao aluno não somente no futuro profissional, mas atenta para a preparação para a vida. Como vimos muitos alunos também esperam isso da instituição escolar.

A respeito da importância da disciplina Geografia para os alunos, constatamos que em sua maioria, na média das três escolas, os alunos pesquisados entendem como sendo a disciplina responsável por estudar o espaço de maneira geral, não detalhando em que aspectos, foram 71 respostas nessa categoria. Conforme Tabela 02, abaixo: 
Tabela 02 - Distribuição dos alunos, por escola, segundo suas justificativas em relação à importância da disciplina Geografia

\begin{tabular}{|c|c|c|c|c|}
\hline \multirow[t]{2}{*}{ PONTOS CITADOS PELOS ALUNOS } & \multicolumn{4}{|c|}{ RESPOSTAS DOS ALUNOS POR ESCOLA } \\
\hline & ESCOLA 1 & ESCOLA 2 & ESCOLA 3 & TOTAL \\
\hline $\begin{array}{l}\text { Relacionados a um melhor } \\
\text { entendimento do espaço }\end{array}$ & $\begin{array}{c}4,4 \% \\
5\end{array}$ & $\begin{array}{c}44,2 \% \\
34\end{array}$ & $\begin{array}{c}40,5 \% \\
36\end{array}$ & $\begin{array}{c}26,9 \% \\
75\end{array}$ \\
\hline $\begin{array}{l}\text { Relacionados a um melhor } \\
\text { entendimento de aspectos sociais, } \\
\text { econômicos, políticos e culturais. }\end{array}$ & $\begin{array}{c}46,9 \% \\
53\end{array}$ & $\begin{array}{c}9,1 \% \\
7\end{array}$ & $\begin{array}{c}6,7 \% \\
6\end{array}$ & $\begin{array}{c}23,6 \% \\
38\end{array}$ \\
\hline $\begin{array}{l}\text { Relacionados a um melhor } \\
\text { entendimento da natureza em seus } \\
\text { aspectos físicos }\end{array}$ & $\begin{array}{c}14,2 \% \\
16\end{array}$ & $\begin{array}{c}13 \% \\
10\end{array}$ & $\begin{array}{c}13,5 \% \\
12\end{array}$ & $\begin{array}{c}13,6 \% \\
38\end{array}$ \\
\hline $\begin{array}{l}\text { Relacionados à Geografia enquanto } \\
\text { disciplina escolar }\end{array}$ & 0 & $\begin{array}{c}5,2 \% \\
4\end{array}$ & $\begin{array}{c}5,6 \% \\
5\end{array}$ & $\begin{array}{c}3,2 \% \\
9\end{array}$ \\
\hline $\begin{array}{l}\text { Relacionados a um melhor } \\
\text { entendimento do lugar onde mora }\end{array}$ & $\begin{array}{c}18,6 \% \\
21\end{array}$ & $\begin{array}{c}20,7 \% \\
16\end{array}$ & $\begin{array}{c}27 \% \\
24\end{array}$ & $\begin{array}{c}22 \% \\
61\end{array}$ \\
\hline $\begin{array}{l}\text { Relacionados a um melhor } \\
\text { entendimento de assuntos do dia a dia }\end{array}$ & $\begin{array}{c}15,9 \% \\
18\end{array}$ & $\begin{array}{c}7,8 \% \\
6\end{array}$ & $\begin{array}{c}7,8 \% \\
6\end{array}$ & $\begin{array}{c}10,7 \% \\
30\end{array}$ \\
\hline TOTAL & 113 & 77 & 89 & 279 \\
\hline
\end{tabular}

Fonte: Pesquisa direta, maio 2009.

No entanto, observamos uma discrepância nessa categoria, enquanto nas Escolas 2 e 3 tivemos maioria 34 e 36 respostas, respectivamente, na Escola 1 , foram apenas 5 alunos que consideram a Geografia importante para se compreender o espaço.

$\mathrm{Na}$ Escola 1 tivemos grande parte das respostas (53) considerando essa disciplina importante por explicar aspectos sociais, como economia, política, cultura. No total das três escolas estudadas foram 66 respostas que citaram algumas dessas esferas que, segundo eles, podem ser entendidas através da Geografia. Esse dado, chama atenção, para uma Geografia dita "humana", que discute os assuntos relativos à sociedade, que constatamos ser predominantes na Escola 1.

Em terceiro lugar, tivemos as justificativas que foram agrupadas na categoria da Geografia ser importante para se entender melhor o lugar onde mora, no qual se observaram 61 respostas que mencionaram que através dessa disciplina passam a conhecer e entender melhor o seu estado, cidade e bairro. É nesse ponto que observamos como se faz importante uma Geografia que esteja voltada para essa realidade, debatendo os conteúdos e tendo em vista as vivências dos alunos nos lugares onde moram, pois assim eles saberão interagir, reconhecer esse conhecimento como sendo algo próximo deles.

Outro dado interessante foi que 30 alunos, sendo a maioria (18) da Escola 1, responderam que a Geografia é importante por ajudá-los a entender fatos do dia a dia, entre os quais citaram: desemprego, violência, falta de moradia, desigualdades sociais, problemas ambientais. Entendemos que esses alunos já conseguem ir além daquele conceito pronto da Geografia como o estudo do espaço, mas identificam esse estudo em questões que eles conhecem de perto, que estão presenciando ou até mesmo vivenciando. É essa Geografia que propomos que ajuda a entender as questões cotidianas, auxiliando em uma melhor reflexão e crítica no meio em que vivemos.

Por último, ainda tivemos justificativas como "A Geografia é importante para passar de ano"

Geografia Ensino \& Pesquisa, v. 16, n.3 p. 107-122 set./dez. 2012.

\footnotetext{
A relação da Geografia e o conhecimento cotidiano vivido no lugar
} ou "é importante porque cai no vestibular", que foram enquadradas na categoria da Geografia enquanto disciplina escolar, na qual tivemos o menor número de respostas (9), ressaltando que nenhum aluno da Escola 1 deu esse tipo de justificativa. Consideramos esse dado como positivo, pois um número muito pequeno dos alunos entende a Geografia como fim em si mesmo, apenas como uma disciplina de escola. Grande parte dos alunos estudados vê a Geografia importante para o seu entendimento do espaço, ou de algum dos seus aspectos ou até mesmo do próprio lugar onde mora e da sua realidade. 
Para identificarmos de que forma os alunos se relacionam com o lugar onde moram, como é o espaço onde vivem, pedimos para eles elencarem os pontos positivos e negativos do bairro em que moram. Dessa forma, pudemos capturar olhares dos alunos sobre seus espaços de vivência; como são atingidos pelos problemas inerentes ao bairro em que moram e ainda que aspectos os fazem criar laços de afetividade e aproximação com o lugar. Pedimos para que elencassem os pontos positivos e os negativos do lugar onde moram.

Sobre os pontos positivos destacados pelos alunos, o que predominou nas três escolas independentemente dos bairros de moradia dos mesmos foi a proximidade ou a facilidade de acesso a vários tipos de serviços, como o comércio, atividades de lazer, transporte, foram 145 respostas que se referiram a esse aspecto.

Observamos o quanto é importante a infraestrutura urbana para esses alunos. Estar próximo dos variados serviços que a cidade oferece é um ponto importante na avaliação dos alunos pesquisados. Outro aspecto mencionado como positivo foi o fato do bairro ser tranquilo, seguro, que foi citado por 37 alunos. Tivemos ainda respostas relacionadas à vizinhança, na qual 23 respostas de alunos afirmam que o seu relacionamento com as pessoas é um fator positivo no seu bairro.

No que se refere aos aspectos considerados negativos citados pelos alunos pesquisados em relação ao bairro onde moram, constatamos que do mesmo modo como o ponto positivo foi citado majoritariamente a proximidade com serviços, o contrário, ou seja, como fator negativo, a falta de algum serviço, que vai desde o comércio, infraestrutura de iluminação, calçamento, saneamento foi mencionada pela maioria dos alunos nas três escolas pesquisadas de maneira geral, totalizando 100 respostas; na Escola 1 foram 53; na Escola 2 foram 26 e na Escola 3 foram 21 respostas. Conforme Tabela abaixo:

Tabela 03- Distribuição dos alunos, por escola, segundo pontos negativos que citaram do bairro onde moram.

\begin{tabular}{|l|l|l|l|l|}
\hline \multirow{2}{*}{$\begin{array}{l}\text { PONTOS CITADOS PELOS } \\
\text { ALUNOS }\end{array}$} & RESPOSTAS DOS ALUNOS POR ESCOLA \\
\cline { 2 - 5 } & ESCOLA 1 & ESCOLA 2 & ESCOLA 3 & TOTAL \\
\hline $\begin{array}{l}\text { Relacionados a considerar o bairro um } \\
\text { lugar inseguro, violento. }\end{array}$ & $31,8 \%$ & $19,5 \%$ & $52,8 \%$ & $32,1 \%$ \\
& 36 & 15 & 47 & 98 \\
\hline $\begin{array}{l}\text { Relacionados com a falta de serviços } \\
\text { (transporte, saneamento, infraestrutura, }\end{array}$ & $47 \%$ & $33,7 \%$ & $23,6 \%$ & $35,8 \%$ \\
lazer) & 53 & 26 & 21 & 100 \\
\hline $\begin{array}{l}\text { Relacionados com o meio ambiente } \\
\text { (poluição sonora, lixo, pouca arborização) }\end{array}$ & $4,4 \%$ & $2,6 \%$ & $5,6 \%$ & $4,3 \%$ \\
\hline $\begin{array}{l}\text { Relacionados com a ocorrência de } \\
\text { enchentes }\end{array}$ & $1,8 \%$ & 2 & 5 & 12 \\
\hline $\begin{array}{l}\text { Relacionado a dificuldades econômicas } \\
\text { (desemprego, desigualdades sociais) }\end{array}$ & $11,4 \%$ & $15,6 \%$ & $1,1 \%$ & $5,4 \%$ \\
\hline Não responderam & 13 & 12 & 1 & 15 \\
\hline TOTAL & $3,6 \%$ & $5,5 \%$ & $2,2 \%$ & $7,2 \%$ \\
\hline
\end{tabular}

Fonte: Pesquisa direta, maio 2009.

Como podemos notar, somente na Escola 3 esse não foi o fator mais citado, sendo a insegurança e a violência o aspecto negativo mais referido pelos alunos dessa escola. A falta de algum serviço foi o aspecto que ficou em segundo lugar dentre os mais citados no geral das três escolas, com 98 respostas no total.

Observamos novamente um grande número de não respondentes (34), alunos que não citaram nenhum aspecto negativo do bairro onde moram. Foram ainda mencionados aspectos como

Geografia Ensino \& Pesquisa, v. 16, n.3 p. 107-122 set./dez. 2012.

Santos, L. P.

ISSN 2236-4994 113 
dificuldades econômicas como falta de oportunidades de emprego e desigualdades sociais por 20 alunos, destacando que foi na Escola 1 que esse tipo de problema foi mais elencado, com 13 respostas.

A ocorrência de enchentes com 15 respostas também apareceu como ponto negativo, ressaltando que foi predominantemente nos alunos da Escola 2, com 12 respostas ligadas a esse fato. Problemas ambientais como lixo, poluição sonora foram mencionados como fator negativo por 12 alunos, somando as três escolas.

Constatamos como os alunos pesquisados avaliam o seu bairro elegendo o que acham de positivo e os problemas a serem sanados. Ao fazer essa análise nos deparamos com o fato de que esses alunos em seus variados bairros de origem convivem com realidades distintas e as percebem de maneiras peculiares.

Tendo em vista as respostas dadas pelos alunos pesquisados, constatamos o quanto eles têm pra contar, o quanto o seu bairro é rico em experiências, de como a convivência em um determinado lugar implica uma dinâmica própria com conflitos, com formas de ver o mundo: "A história do indivíduo é aquela que produziu o espaço e que a ele se imbrica por isso que ela pode ser apropriada. Mas é também uma história contraditória de poder e de lutas, de resistências compostas por pequenas formas de apropriação." (CARLOS, 2007, p.19)

Concluímos ainda através dessas respostas, o quanto os alunos vivenciam a Geografia no seu dia a dia, quando convivem com as mazelas urbanas, como a falta de infraestrutura decorrente do crescimento desordenado das cidades, do desemprego, da insegurança, das desigualdades sociais, do lixo nas ruas, da poluição sonora, das enchentes que pra realidade teresinense é um assunto muito atual.

É essa a Geografia para além da sala de aula, o contato que temos como espaço, que aprendemos na prática, no nosso próprio bairro, onde podemos presenciar a segregação espacial, as consequências dos descuidados com o meio ambiente, que podem causar muitos prejuízos, um deles as enchentes que atingiram o Piauí. A localização urbana, os problemas econômicos, a influência do clima na nossa vida. É no lugar que está o plano mais conhecido pelo sujeito, onde se efetiva a sua relação com o espaço, identificar esses pontos e usá-los pode ser muito enriquecedor na aula de Geografia.

Como vimos todos esses temas mencionados pelos próprios alunos ao falar do lugar onde moram podem ser discutidos na disciplina Geografia e o que é melhor pode ser enriquecido com a experiência dos próprios alunos, que sofrem na pele as suas consequências.

O conteúdo trazido pelos livros didático muitas vezes não aborda esses problemas que são específicos de cada região, somente quem vive diariamente em lugar pode identificar as consequências da organização desse espaço na sua vida.

Quando perguntados se usavam os conhecimentos que adquiriam com a disciplina Geografia no seu cotidiano, os alunos em sua maioria responderam que sim, na Escola 1 (82,3\%), na Escola 2 $(79,2 \%)$ e na Escola $3(72,0 \%)$ na qual observamos o menor total. Conforme podemos observar na Tabela 04, os alunos pesquisados afirmam que utilizam a Geografia no seu dia a dia. Esses dados nos revelam que de alguma forma eles já percebem a disciplina Geografia um sentido prático, conseguindo aplicá-la ou identificá-la na sua realidade.

Tabela 04 - Distribuição dos alunos por escola, segundo o uso dos conhecimentos adquiridos com a disciplina geografia no dia a dia, Teresina-PI

Geografia Ensino \& Pesquisa, v. 16, n.3 p. $107-122$ set./dez. 2012

A relação da Geografia e o conhecimento cotidiano vivido no lugar

\begin{tabular}{|l|c|c|}
\hline \multirow{2}{*}{ ESCOLAS } & \multicolumn{2}{|c|}{$\begin{array}{l}\text { USO DOS CONHECIMENTOS ADQUIRIDOS COM A DISCIPLINA } \\
\text { GEOGRAFIA NO DIA A DIA }\end{array}$} \\
\cline { 2 - 3 } & SIM & NÃO \\
\hline Escola 01 & $82,3 \%$ & $17,7 \%$ \\
\hline Escola 02 & 93 & 20 \\
\hline Escola 03 & $79,2 \%$ & $20,8 \%$ \\
\hline Total & 61 & 16 \\
\hline
\end{tabular}

Fonte: Pesquisa direta, maio 2009. 
Outro dado que constatamos foi que grande parte dos alunos pesquisados $(90,3 \%)$ no total das três escolas considera a aula de Geografia um momento em que se pode discutir assuntos cotidianos, o que está demonstrado na Tabela 05. Dos que responderam que não consideram 0 maior número se encontram na Escola 2 (14,6\%) dos pesquisados.

Tabela 05 - Distribuição dos alunos por escola, segundo a consideração da aula de geografia como um momento em que se podem discutir assuntos cotidianos, Teresina-PI

\begin{tabular}{|l|c|c|}
\hline \multirow{2}{*}{ ESCOLAS } & \multicolumn{2}{|c|}{ USO DOS CONHECIMENTOS ADQUIRIDOS COM A } \\
& DISCIPLINA GEOGRAFIA NO DIA A DIA \\
\cline { 2 - 3 } & SIM & NÃO \\
\hline Escola 01 & $93 \%$ & $7,8 \%$ \\
& 105 & 8 \\
\hline Escola 02 & $84,4 \%$ & $14,6 \%$ \\
& 65 & 12 \\
\hline Escola 03 & $91 \%$ & $9 \%$ \\
& 81 & 7 \\
\hline Total & $90,3 \%$ & $9,7 \%$ \\
& 252 & 27 \\
\hline
\end{tabular}

Fonte: Pesquisa direta, maio 2009.

Nas três escolas estudadas, os alunos veem o momento da aula como uma oportunidade em se tratar da sua própria realidade, ou seja, uma chance de discussão e de esclarecimentos, em que podem participar contando fatos vivenciados por eles próprios; dessa forma, contribuem para um aprendizado mais direcionado para a prática, enriquecendo a aula com suas próprias experiências, deixando de ser passivo e passando a construir conhecimento.

Constatamos que a maioria dos alunos pesquisados afirma participar das aulas contando assuntos do seu cotidiano, na Escola 1 (68,1\%), na Escola 2 (80,5\%) e na Escola 3 (59,5\%). No entanto, ainda há um grande percentual de alunos que admite não participar da aula $(31,2 \%)$.

Um fato interessante a ressaltar é que foi na Escola 2 que observamos o maior número de alunos que afirma participar da aula; justamente nesta, escola tem-se maior a quantidade de alunos trabalhadores, o que pode significar mais experiências ou mais desenvoltura para contá-las. Como pode ser visualizado através da Tabela 06 .

Tabela 06 - Distribuição dos alunos por escola, segundo a participação nas aulas de geografia comentando assuntos cotidianos, Teresina-PI

\begin{tabular}{|l|c|c|}
\hline \multirow{2}{*}{ ESCOLAS } & \multicolumn{2}{|c|}{ USO DOS CONHECIMENTOS ADQUIRIDOS COM A } \\
& DISCIPLINA GEOGRAFIA NO DIA A DIA \\
\cline { 2 - 3 } & SIM & NÃO \\
\hline Escola 01 & $68,1 \%$ & $31,9 \%$ \\
& 77 & 36 \\
\hline Escola 02 & $80,5 \%$ & $19,5 \%$ \\
& 62 & 15 \\
\hline Escola 03 & $59,5 \%$ & $40,5 \%$ \\
& 53 & 36 \\
\hline Total & $68,8 \%$ & $31,2 \%$ \\
& 192 & 87 \\
\hline
\end{tabular}

Geografia Ensino \& Pesquisa, v. 16, n.3 p. 107-122 set./dez. 2012.

Santos, L. P. 
Ainda sobre como os alunos relacionam o que aprendem em Geografia e o seu cotidiano, pedimos para citarem os conteúdos de Geografia, que se relacionam diretamente com a sua realidade, com o lugar em que moram, e obtivemos as respostas, que podem ser visualizadas na Tabela 07, abaixo:

Tabela 07- distribuição dos alunos, por escola, segundo assuntos de geografia que eles consideram ter relação com a sua vida.

\begin{tabular}{|c|c|c|c|c|}
\hline \multirow[t]{2}{*}{ PONTOS CITADOS PELOS ALUNOS } & \multicolumn{4}{|c|}{ RESPOSTAS DOS ALUNOS POR ESCOLA } \\
\hline & ESCOLA 1 & ESCOLA 2 & ESCOLA 3 & TOTAL \\
\hline \multirow{2}{*}{$\begin{array}{l}\text { Relacionados ao estudo da natureza (clima, } \\
\text { solo, relevo, vegetação, hidrografia, geologia) }\end{array}$} & $22,1 \%$ & $19,5 \%$ & $18 \%$ & $20 \%$ \\
\hline & 25 & 15 & 16 & 56 \\
\hline \multirow{2}{*}{$\begin{array}{l}\text { Relacionados ao estudo da sociedade } \\
\text { (aspectos sociais, econômicos, políticos e } \\
\text { culturais) }\end{array}$} & $17,7 \%$ & $19,5 \%$ & $22,5 \%$ & $19,7 \%$ \\
\hline & 20 & 15 & 20 & 55 \\
\hline \multirow{2}{*}{$\begin{array}{l}\text { Relacionados ao meio ambiente (problemas } \\
\text { ambientais) }\end{array}$} & $8,0 \%$ & $18,2 \%$ & $11,2 \%$ & $11,8 \%$ \\
\hline & 9 & 14 & 10 & 33 \\
\hline \multirow{2}{*}{$\begin{array}{l}\text { Relacionados à localização no espaço } \\
\text { (mapas, fuso horário, regionalização do } \\
\text { espaço) }\end{array}$} & $17,7 \%$ & $19,5 \%$ & $21,3 \%$ & $19,3 \%$ \\
\hline & 20 & 15 & 19 & 54 \\
\hline \multirow{2}{*}{$\begin{array}{l}\text { Relacionados ao lugar onde mora (bairro, } \\
\text { cidade, estado) }\end{array}$} & $27,4 \%$ & $14,3 \%$ & $19,1 \%$ & $21,2 \%$ \\
\hline & 31 & 11 & 17 & 59 \\
\hline \multirow[t]{2}{*}{ Todos } & $6,5 \%$ & $6,5 \%$ & $4,5 \%$ & $5 \%$ \\
\hline & 5 & 5 & 4 & 14 \\
\hline \multirow[t]{2}{*}{ Nenhum } & $2,7 \%$ & $2,5 \%$ & $3,4 \%$ & $3,0 \%$ \\
\hline & 3 & 2 & 3 & 8 \\
\hline TOTAL & 113 & 77 & 89 & 279 \\
\hline
\end{tabular}

Fonte: Pesquisa direta, maio 2009.

Conforme os dados apresentados na Tabela 07, constatamos que os alunos conseguem interligar mais facilmente os conhecimentos geográficos com a sua realidade quando tratam sobre o lugar em que moram, seu bairro, cidade e estado. Nessa categoria, tivemos 59 respostas, sendo que o maior número foi na Escola 1, 31 respostas.

Com quantidades de respostas muito próximas, muito parecidas, vieram: assuntos relacionados a aspectos naturais ( 56 respostas), assuntos sobre os aspectos sociais ( 55 respostas) e relacionados à localização ou regionalização do espaço (54 respostas). Dentre os conteúdos citados, destacamos o tempo atmosférico, que foi muito elencado pelos alunos (talvez porque a cidade passava no período da pesquisa pelo problema das enchentes que atingiu os alunos direta ou indiretamente); as atividades econômicas, desemprego (aspectos sociais); no que se refere à localização e regionalização, conteúdos como mapas, pontos cardeais, divisão das cidades, zona rural, zona urbana, fusos horários foram os mais mencionados pelos alunos ao relacionar a Geografia com a realidade vivida por eles.

Tivemos ainda os alunos que citaram os conteúdos ligados ao meio ambiente: foram 33

Geografia Ensino \& Pesquisa, v. 16, n. 3 p. 107-122 set./dez. 2012.

A relação da Geografia e o conhecimento cotidiano vivido no lugar respostas que aludiram problemas ambientais como poluição, desmatamento, aquecimento global, conservação da água, proteção dos animais, desenvolvimento sustentável e ainda a necessidade de todos preservarem a natureza.

Outro tipo de resposta que observamos foi a dos alunos que consideram que todos os conteúdos estudados na disciplina Geografia estão relacionados com a sua realidade: foram 14 respostas nesse sentido. Por outro lado, tivemos também os alunos que não conseguiram fazer 
essa relação entre os conhecimentos geográficos e a sua realidade (8 respostas), afirmando que nenhum assunto discutido na aula de Geografia tem haver com o que ele vive.

A partir da análise desses dados, concluímos que a grande maioria dos alunos consegue relacionar, de alguma forma, algum conteúdo estudado na disciplina Geografia com a sua própria realidade.

Para saber ainda de que forma os alunos identificam a disciplina Geografia ou de que forma ainda os alunos pesquisados se lembram dessa disciplina, perguntamos que palavras os fazem lembrar a Geografia, assim puderam enumerar os assuntos que mais the chamam atenção ou despertam seu interesse ou ainda aqueles que foram mais repetidos durante a sua formação escolar. As respostas foram as mais variadas possíveis, permeando vários campos da ciência geográfica, enquadramos em algumas categorias, o que pode ser visualizado na Tabela 08.

Tabela 08- distribuição das palavras citadas pelos alunos, por escola, segundo livre associação com a geografia.

\begin{tabular}{|l|c|c|c|c|}
\hline \multirow{2}{*}{ PONTOS CITADOS PELOS ALUNOS } & \multicolumn{4}{|l|}{ RESPOSTAS DOS ALUNOS POR ESCOLA } \\
\cline { 2 - 5 } & ESCOLA 1 & ESCOLA 2 & ESCOLA 3 & TOTAL \\
\hline $\begin{array}{l}\text { Relacionados ao estudo da natureza } \\
\text { (clima, solo, relevo, vegetação, hidrografia, } \\
\text { geologia) }\end{array}$ & $35,4 \%$ & $29,9 \%$ & $36 \%$ & $34 \%$ \\
\hline $\begin{array}{l}\text { Relacionados ao estudo da sociedade } \\
\text { (aspectos sociais, econômicos, políticos e } \\
\text { culturais) }\end{array}$ & $22,2 \%$ & $20,8 \%$ & $25,8 \%$ & $23 \%$ \\
\hline $\begin{array}{l}\text { Relacionados ao meio ambiente } \\
\text { (problemas ambientais) }\end{array}$ & $7,0 \%$ & 16 & 23 & 64 \\
\hline $\begin{array}{l}\text { Relacionados à localização no espaço } \\
\text { (mapas, fuso horário, regionalização do } \\
\text { espaço) }\end{array}$ & $29,2 \%$ & $35 \%$ & $16,8 \%$ & $27 \%$ \\
\hline $\begin{array}{l}\text { Relacionados ao lugar onde mora (bairro, } \\
\text { cidade, estado) }\end{array}$ & $6,2 \%$ & $5,2 \%$ & $6,7 \%$ & 75 \\
\hline TOTAL & 7 & 4 & 6 & $6 \%$ \\
\hline
\end{tabular}

Fonte: Pesquisa direta, maio 2009.

Observamos que a categoria do estudo da natureza foi a que teve o maior número de respostas (95); a maioria dos alunos citou aspectos naturais como clima, solo, rios, montanhas, planaltos, temperatura, hidrografia, vegetação, rochas. Importante ressaltar que este tipo de resposta foi maioria nas três escolas pesquisadas. Destacamos ainda que o tempo atmosférico foi 0 aspecto mais citado e acreditamos que isso ocorreu porque era um tema bastante discutido na cidade, devido aos motivos já elencados anteriormente.

Em segundo lugar ficaram as palavras relacionadas à regionalização do espaço, como cidade, país, região, território, lugar, países, continentes, bairro e ainda as relacionadas à localização, como mapas (27\%), fuso horário, latitude, longitude; nessa categoria, obtivemos 75 respostas.

Outros aspectos muito citados pelos alunos (64 respostas) foram os que se enquadram no estudo da sociedade, entre eles, foram citadas palavras como: emprego, desemprego, população, guerras, sociedade, cultura, socialismo, capitalismo, geopolítica, IDH, crise econômica. Observamos que algumas dessas palavras estão muito relacionadas a assuntos cotidianos, como a busca pelo emprego, os problemas econômicos, as notícias de conflitos entre países que são vinculadas pelos veículos de comunicação.

Constatamos a ocorrência de palavras relacionada a meio ambiente (28), referências a problemas ambientais que muito são discutidos atualmente pelos meios de comunicação; foram mencionadas: problemas ambientais, poluição, desenvolvimento sustentável, reciclagem, preservação ambiental.

Geografia Ensino \& Pesquisa, v. 16, n.3 p. 107-122 set./dez. 2012.

Santos, L. P. 
Tivemos ainda respostas relacionadas com o próprio ambiente escolar, que remetem a Geografia apenas como uma disciplina que se tem que estudar para fazer uma prova ou para prestar vestibulares, foram 17 respostas nesse sentido.

Sobre essa associação, constatamos que os alunos, em sua maioria, relacionam a Geografia aos aspectos físicos do espaço, sua própria organização e ainda à sociedade. Observamos que as palavras citadas podem nos remeter a variadas percepções que esses alunos têm sobre essa disciplina e ainda sobre a forma como se relacionam com o mundo. Para uns, o meio natural chama mais atenção, e a discussão sobre esses elementos lhe despertam mais interesse; a sociedade, 0 meio ambiente são partes do cotidiano desses alunos que conseguem relacionar essas realidades à disciplina Geografia, estudada na escola.

\section{Discussão dos resultados}

Queremos destacar a principal conclusão que ficou através desta pesquisa, que foi a importante contribuição que pode ser dada pelos alunos nas aulas de Geografia. A sua convivência em um lugar específico traz para a sua vida diversas formas de se relacionar na sociedade, como por exemplo: que atividades de lazer frequenta, que tipos de serviço tem acesso, mais ou menos oportunidades de emprego, um meio ambiente mais ou menos saudável, mais mobilidade dentro de uma cidade, relacionamentos nos mais variados grupos sociais e culturais.

Através do lugar onde mora, o aluno entra em contato como o mundo, efetiva experiências; dessa forma, consideramos imprescindível que essa parcela do espaço seja trazida para a sala de aula.

Essas realidades conhecidas pelos alunos constituem-se nas suas vivências, ou seja, aquilo que eles já conhecem sobre o espaço, sobre a sociedade de como estão imbuídos nesse processo. Muitas vezes, esse contexto não é conhecido pelo professor, muito menos levado para a sala de aula:

Sabemos que o sujeito traz consigo uma carga de experiências e de conhecimentos sistematizados ou não, realidades vividas muitas vezes impossíveis de serem representadas pelos professores. No entanto, pelo que temos discutido em diferentes encontros, cada vez mais acreditamos que tais vivências devam ser aproveitadas, problematizadas e textualizadas, buscando-se, assim, a inserção da vida na escola, tornando a escola, efetivamente integrada á vida. (CASTROGIOVANI, 2007, p. 43)

Através desta pesquisa, constatamos o quanto essas vivências são ricas, como os alunos têm a contribuir nesse processo e ainda de como eles esperam que a escola (a maioria dos alunos pesquisados considera essa instituição importante para lhe proporcionar um melhor aprendizado e um futuro melhor) e que a Geografia os auxiliem na compreensão do mundo e da sua própria realidade.

A seguir transcrevemos algumas respostas dadas pelos alunos, que nos evidenciaram isso quando definiram a importância da disciplina Geografia: "Para sabermos mais sobre o meio

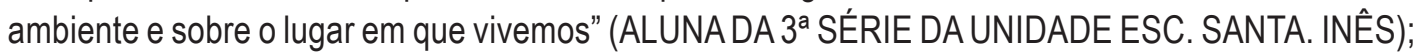
"Nos ensina a entender os fatos que acontecem no nosso país e no mundo" (ALUNA DA $1^{\text {a }}$ SÉRIE DA UNIDADE ESC. SANTA. INÊS); "Traz um conhecimento aprofundado sobre o espaço onde vivemos e do espaço ao nosso redor" (ALUNO DA $1^{\text {a }}$ SÉRIE DO C. E. Z. DE GÓIS). Percebemos através dessas falas uma expectativa desses alunos sobre a Geografia, que eles realmente possam

Geografia Ensino \& Pesquisa, v. 16, n.3 p. 107-122 set./dez. 2012.

\footnotetext{
A relação da Geografia e o conhecimento cotidiano vivido no lugar
} entender melhor o espaço, não somente aquele distante que está nas fotografias dos livros, mas também aquele vivido por eles.

Destacamos ainda outro ponto relevante: a posição do professor quanto a esse conhecimento que 0 aluno já possui e ainda sobre o seu conhecimento dos alunos. É preciso fazer perguntas como: A quem se vai ensinar? Como são os alunos? Como eles veem a Geografia no seu dia a dia? Que dificuldades eles têm? Esses questionamentos poderiam auxiliar esse professor na sua prática, de modo que ele assumisse posturas socioconstrutivistas em suas aulas: 
Quando o professor defronta-se com a realidade da Geografia escolar e reflete sobre ela, pode distinguir dois tipos de práticas, uma que é instituída, tradicional; outra que são as práticas alternativas, que já é realidade em muitos casos. De um lado, uma prática marcada por mecanismos conhecidos de antemão: a reprodução de conteúdos, a consideração de conteúdos como inquestionáveis, acabados, o formalismo, o verbalismo, a memorização. De outro, algumas experiências e alguns encaminhamentos que começam a ganhar consistência, fundamentados, em muitos casos, em visões construtivistas do ensino. (CAVALCANTI, 2005, p. 66)

A ruptura com essas posturas tradicionais, no entanto, não é uma tarefa fácil. Através do diálogo com os seis professores entrevistados nesta pesquisa, constatamos o quanto eles reconhecem a necessidade de se assumir novas metodologias, concedendo um espaço maior aos alunos, afirmando até que, quando fazem isso, os alunos participam mais, contam fatos do cotidiano, interagem e se interessam mais. Por outro lado, esses mesmos professores se deparam com dificuldades que os impedem ou dificultam a execução de tais propostas.

Dentre essas dificuldades, podemos citar a falta de estrutura das escolas, as deficiências na formação desse profissional, a má remuneração, que o impede de ter acesso a mais recursos didáticos, a mais fontes de informação e ainda a participar de mais cursos. Além disso, essa falta de infraestrutura no seu trabalho pode causar ainda a desmotivação desse profissional.

Muitas foram as dificuldades enumeradas, desde a falta de recursos, pouca leitura dos alunos, pequena carga horária, até mesmo o incentivo da escola. Além dessas barreiras, existem aquelas que sabemos da sua existência, mas que ficaram veladas, mas são impossíveis de serem mascaradas, como a precária formação, falta de material didático, os baixos salários, conforme nos mostra Cabreira:

É muito comum hoje o professor ter como sua única fonte de estudo e pesquisa os livros didáticos. E aí podemos elencar vários motivos: o custo em geral alto dos livros e a dificuldade de interpretar os textos que estão fora da linguagem dos livros didáticos são alguns exemplos. Em muitos casos, o próprio livro didático é que norteia os estudos em nível superior. [...] A ampliação da oferta, neste nível de ensino não significou a manutenção da qualidade da formação do professor, que vai se tornando cada vez mais precária. Não podemos esquecer que, no Brasil, a formação dos professores é assentada no binômio trabalho e estudo. [...] Se esse contexto permite, por um lado, a troca entre colegas e com os alunos, por outro, priva o professor da possibilidade de ampliar a sua formação. (CABREIRA, 2001, p. 101)

Outro ponto que constatamos foi que a efetivação de uma prática que valorize esse conhecimento do aluno desperta mais interesse, tornando essa disciplina atrativa, como escreveu esta aluna da $3^{\mathrm{a}}$ série do Colégio Estadual Zacarias de Góis:

Acho que a disciplina geografia não é mais só aquela que fala da divisão do mundo, climas e outros assuntos, acho que a disciplina geografia melhorou muito, não era uma disciplina que eu gostasse, mas hoje através das aulas eu fico mais informada do que realmente acontece no mundo e na minha cidade.

Como vimos, a Geografia pode se tornar muito atrativa e esclarecedora, quando traz mais concatenados os conteúdos e a realidade dos alunos, como podemos perceber ainda na fala de dois outros alunos: "Em todo lugar em que estamos temos que saber um pouco de Geografia para entender o que acontece" (ALUNO DA 2 a SÉRIE DA U.E.P. M. L. REBELO) e "O clima, por exemplo, ajuda a gente saber por que ocorrem as chuvas que causam alagamento e inundações" (ALUNA DA12a SÉRIE DA U.E.P. M. L. REBELO)

Geografia Ensino \& Pesquisa, v. 16, n.3 p. 107-122 set./dez. 2012.

Santos, L. P.

ISSN 2236-4994 119 
Quando se faz essa ligação, os alunos são capazes de interpretar os fenômenos de outra forma, entendendo o que os ocasionou, é a Geografia não mais como um conhecimento distante, mas presente na sua própria realidade:

Assim, professor e aluno estarão envolvidos em situações de aprendizagem que consideram o empírico, o reconhecimento do que existe no lugar, os conhecimentos que 0 aluno traz consigo a partir de suas vivencias, e a busca de teorização destas verdades. Contextualizando-as os alunos fazem as abstrações necessárias, trabalhando com os conceitos científicos e desencadeando a compreensão que permite ir cada vez mais além no sentido de generalizar experiências particulares e entender a realidade de forma mais ampla. (CALLAI, 2000, p. 103)

Por último, queremos destacar alguns pontos importantes sobre a análise dos dados concedidos pelos alunos: a Geografia é uma disciplina que desperta interesse, no entanto muitas vezes não consegue levar o aluno a identificá-la na sua própria realidade; quando se trata o bairro, a cidade do aluno abrindo espaço para ele participar há um maior interesse. Essas são apenas algumas impressões que tivemos ao ouvir esses alunos; 0 aspecto que mais nos chamou atenção foi o quanto esses alunos têm a dizer; é preciso que eles sejam mais ouvidos; suas experiências podem auxiliar na construção do conhecimento, ademais se tratando da Geografia.

\section{Considerações Finais}

Atualmente os alunos estão muito expostos a diversos tipos de informações recebidas pelos mais diferentes meios de comunicação, desta forma, esperam que a escola os auxiliem não somente a adquirir mais conhecimentos e prepará-los para o mercado de trabalho, mas também esperam que essa instituição lhes prepare para exercer a cidadania e lhes dê conhecimentos práticos para o dia a dia.

Sobre a relação dos alunos com a disciplina Geografia, entendemos que eles convivem com as mazelas urbanas, como a falta de infraestrutura das cidades, o desemprego, a insegurança, as desigualdades sociais, o lixo nas ruas, a poluição sonora, as enchentes. Todos esses temas podem ser trazidos à tona nas aulas de Geografia, trazendo essas experiências dos alunos juntamente com o conhecimento geográfico; dessa forma, edificando-se um conhecimento significativo para 0 aluno.

Essas são algumas questões que discutimos a partir desta pesquisa, que indicou que esse resgate das vivências, a consideração do lugar do aluno pode ser um caminho a ser tomado e que tem uma contribuição muito importante nas aulas de Geografia. $O$ que ficou foi a certeza de que cada vez mais é necessário se refletir sobre o ensino e as formas como esse pode contribuir para a formação de cidadãos críticos.

\section{Referencias Bibliográficas}

CABREIRA, Márcia Maria. Parâmetros nacionais curriculares e o ensino de geografia: algumas reflexões. Dialogia V. 0 Out/2001.

Geografia Ensino \& Pesquisa, v. 16, n.3 p. 107-122 set./dez. 2012.

A relação da Geografia e o conhecimento cotidiano vivido no lugar
CALLAI, H. C.; CASTROGIOVANNI, A. C. (Org.). Estudar o lugar para compreender o mundo. In: Ensino de Geografia: práticas e textualizações no cotidiano. Porto Alegre: Mediação, 2000. p. 83-92.

CALLAI, Helena Copeti. A geografia e a escola: muda a geografia Muda o ensino? Terra Livre, São Paulo, n.16, p 135-152, $1^{\circ}$ semestre/2001. 
Aprendendo a ler o mundo: a geografia nos anos iniciais do ensino fundamental. Cedes, Campinas, vol. 25, n. 66, p. 227-247, mai/ago. 2005.

CARLOS, Ana Fani Alessandri. O lugar no/do mundo. São Paulo: Labur Edições, 2007a.

O Espaço Urbano: Novos Escritos sobre a Cidade. São Paulo: Labur Edições, 2007 b.

CASTELLAR, Sônia (org.) Educação Geográfica: teorias e práticas docentes. São Paulo: contexto, 2005.

jul./set. 2000.

A alfabetização em Geografia. Espaços da Escola, ljuí, v. 10, n. 37, p. 29-46,

A formação de professores e o Ensino de Geografia. In: As transformações no mundo da Educação: Geografia, Ensino e Responsabilidade Social. Terra Livre, n 14. São Paulo: AGB, Janeiro - julho, 1999.

CASTROGIOVANI, Antônio Carlos. et al. (org.) Geografia em sala de aula: práticas e reflexões. 4. ed. Porto Alegre: editora da UFRGS, 1999.

Ensino de Geografia: Práticas e textualização no cotidiano. 2. ed. Porto Alegre:

Mediação, 2002.

CASTROGIOVANI, Antônio Carlos. et al. (org.) Geografia em sala de aula: práticas e reflexões. 4. ed. Porto Alegre: editora da UFRGS, 2003.

CAVALCANTI, Lana de Souza. Geografia, Escola e construção de conhecimento. São Paulo: Papirus, 2001.

Ensino de geografia e diversidade: construção de conhecimentos geográficos escolares e atribuição de significados pelos diversos sujeitos do processo de ensino. In: CASTELLAR, Sonia (org.) Educação geográfica: teorias e práticas docentes. São Paulo: contexto, 2005.

.Geografia e práticas de ensino. Goiânia: Alternativa, 2002.

FREIRE, P. Pedagogia da autonomia: saberes necessários a prática educativa. 18. ed. São Paulo: Paz \& Terra, 2001.

KAERCHER, Nestor André et al. A Geografia no ensino médio. In: CASTROGIOVANI, Antônio Carlos. et al. (org.). Geografia em sala de aula: práticas e reflexões. 4. ed. Porto Alegre: editora da UFRGS, 1999a.

A geografia é o nosso dia-a-dia. In: CASTROGIOVANI, Antônio Carlos. et al. (org.) Geografia em sala de aula: práticas e reflexões. 4. ed. Porto Alegre: editora da UFRGS, 1999b.

.Geografizando o jornal e outros cotidianos: práticas em Geografia para além do livro didático. In: CASTROGIOVANI, Antônio Carlos. et al. (org.) Ensino de Geografia: Práticas e textualização no cotidiano. 2. ed. Porto Alegre: Mediação, 2002.

O gato comeu a geografia critica? Alguns obstáculos a serem superar no ensinoaprendizagem de geografia. In: PONTUSCHKA, Nídia Nacib, OLIVEIRA, Ariovaldo Umbelino (org). Geografia em Perspectiva. São Paulo: Contexto, 2002.p.221-231.

Desafios e utopias no ensino de geografia. 1 ed. Santa Cruz do Sul:

Geografia Ensino \& Pesquisa, v. 16, n.3 p. 107-122 set./dez. 2012. 
OLIVEIRA, Ariovaldo Umbelino de. Educação e ensino de geografia na realidade brasileira. In: OLIVEIRA, Ariovaldo Umbelino de (org.). Para onde vai o ensino de Geografia? 7. ed. São Paulo: contexto, 2001, p.135-44. (Repensando o ensino)

RESENDE, Márcia M. Spyer. O saber do aluno e o ensino de Geografia. In_ VESENTINI, José William (org.) Geografia e ensino: textos críticos. 6. ed. São Paulo: Papirus, 2002. p. 83-117.

RICHARDSON, Roberto Jarry. Pesquisa Social: métodos e técnicas. São Paulo: Atlas, 2007.

SACRAMENTO, Ana Claudia Ramos. O currículo na construção do conhecimento geográfico: um estudo da ação docente nas escolas estaduais de São Paulo. Dissertação de Mestrado. 2007. 291f. Faculdade de Educação da Universidade de São Paulo, São Paulo.

SANTOS, Milton. Metamorfose do espaço habitado, fundamentos Teórico e metodológico da geografia. Hucitec. São Paulo 1988.

Por uma outra globalização: do pensamento único à consciência universal. Rio de Janeiro; São Paulo: Record: 2000.

A Natureza do Espaço: Técnica e Tempo, Razão e Emoção - 4. ed. São Paulo: Editora da Universidade de São Paulo, 2006.

SANTOS, Giovana Aparecida dos. Desafios no processo ensino-aprendizagem do lugar nas séries iniciais do ensino fundamental: possibilidades para a formação da cidadania. 2006. 104f. Dissertação de Mestrado. Universidade Estadual Paulista, Rio Claro.

VLACH, Vânia Rúbia Farias. Geografia em construção. Minas Gerais: Editora Lê, 1991.

\section{Correspondência:}

Laudenides Pontes dos Santos - Rua Mestre Bibio, 4801, bloco 20, apto 203. Parque Ideal. CEP. 64077845. Teresina- PI

E-mail: laudenidesp@yahoo.com.br

Recebido em 17 de março de 2012.

Revisado pelo autor em 04 de setembro de 2012.

Aceito para publicação em 19 de setembro de 2012. 